"Morton G. White, "Value and Obligation in Dewey and Lewis," Philosophical Review, July 1949. A related distinction is made by Wilfrid Sellars in "Aristotelian Philosophies of Mind" in R. W. Sellars, V. J. McGill, and Marvin Farber, ed., Philosophy for the Future (New York, 1949).

An Analysis of Knowledge and Valuation, p. 525.

Ibid., p. 529.

'Ibid., p. 540.

Ibid., pp. 524-25.

\title{
Some Arguments for Non-Naturalism about Intrinsic Value
}

\author{
by WILLIAM K. FRANKENA
}

\author{
UNIVERSITY OF MICHICAN
}

Ethical intuitionists may be described as holding that certain ethical terms stand for characteristics which are indefinable and non-natural. In twentieth-century literature this claim has been made primarily for the term "good" in the usage in which it is short for "intrinsically good," whereas it had previously been made mainly for such words as "right," "ought," and "fitting." Now, the arguments to prove that "good" (in the sense of "intrinsically good") stands for an indefinable characteristic have been frequently, if not definitively, discussed; but those to show that it stands for a non-natural characteristic, so far as they are distinct from the former, have not, to my knowledge, been dealt with at all. It is, therefore, my purpose to take up these latter arguments here and to show that they quite fail to prove their point.

When they say that goodness ${ }^{1}$ is a non-natural characteristic, the intuitionists mean to say one or more of three things: (a) it is nonempirical, (b) it is in a certain sense consequential or resultant, (c) it is in some way nondescriptive. ${ }^{2}$ Thus it is one or more of these statements that they are trying to establish when they contend that goodness is non-natural. C. D. Broad, for instance, describes a non-natural property as one the concept of which is nonempirical, and argues as follows to show that goodness is non-natural in this sense, if it is a property at all. ${ }^{3}$ (1) It seems evident that goodness is not a characteristic of which we become aware by inspecting our sense-data. (2) It seems equally clear that goodness cannot be identified with any simple psychological characteristic such as we could 
discover by introspecting our experiences; no one who is tempted to identify it with one of these psychological characteristics will do so if he recognizes the distinction between goodness itself and a good-making characteristic. (3) Therefore, if goodness is a simple quality, then it is "almost certainly" non-natural. (4) But no proposed definition of goodness in purely natural terms is in the least plausible. (5) Therefore, if goodness is a complex characteristic, then again it is almost certainly non-natural. (6) Hence, finally, if there is such a characteristic as goodness at all, then, "according to our criterion," it will almost certainly be non-natural.

Probably no one except an extreme behaviorist will question step (1). But very many writers would object to step (4), and, in view of the number of able men among them, it seems hardly reasonable to assert that no proposed naturalistic analysis of goodness is in the least plausible. It would be reasonable to say that no such analysis of goodness is correct, but this Broad does not show. In step (2) Broad is similarly dogmatic. If enjoyableness is a simple psychological characteristic, it is not obvious to me, at any rate, that (intrinsic) goodness cannot be identified with any such characteristic; one could, at any rate, identify goodness with enjoyableness and still admit the distinction between goodness and good-making characteristics, just as Broad himself admits the distinction between pleasantness and pleasant-making characteristics. But even if it is true that goodness is not identical with any "other" simple psychological characteristic like enjoyableness, it is by no means clear that it is not an indefinable (simple and unique) natural characteristic of an introspectable sort. Merely to affirm that it is not such a characteristic is to beg the question. On the other hand, to assert that inspection reveals goodness not to be on the list of introspectable characteristics may be correct, but it involves admitting that the issue is to be settled by inspection and not by argument, and that what purported to be an argument consisting of six steps was really only an appeal to inspection-which I believe to be the case.

I confess that upon inspection I do not find any indefinable natural property for which the term "good" might be taken to stand when it is used in the sense in which Moore and Broad are interested. Hence I share Broad's opinion to the extent of agreeing that, if goodness is a property which is indefinable in natural terms, then it is almost certainly nonnatural (in his sense, at least). ${ }^{4}$ But $I$ must insist that the antecedent of this hypothetical proposition has not been sufficiently well established (certainly not by Broad in the discussion here in question) for anyone to proceed to the assertion of its consequent.

Miss Clarke suggests an argument to show that goodness is non-natural in Broad's sense when she contends that, if goodness is a resultant property, then it would seem that it must be nonempirical. ${ }^{5}$ This contention is 
somewhat cryptic and hypothetical. Suppose we agree that goodness is a resultant property. In which sense? In the Moore-Ross sense? ${ }^{6}$ Even in that sense, "P is resultant" does not logically entail "P is nonempirical." To get this conclusion we must add the premise, "No empirical property is resultant (in the sense in question)." This premise, however, cannot be asserted until it is known that goodness is not an empirical property. It may be true that, if $\mathrm{P}$ is resultant in the Moore-Ross sense, then it is not identical with any of the "other" properties which we call empirical (and this only follows if none of these properties is resultant in that sense); this would mean that $\mathrm{P}$ is not definable in empirical terms, but it does not follow that $P$ is nonempirical. ${ }^{7}$

Perhaps Miss Clarke means that there is no natural resultant property for which "good" can plausibly be said to stand, so that, if it stands for a resultant property, it must stand for one which is non-natural. Then I can only say that it is not clear, and she does not show, that there is no natural resultant property (definable or indefinable) which "good" may be said to denote, or that "good" does denote a property which is resultant (in the Moore-Ross sense, at least).

In his recent reply to his critics, G. E. Moore seems to take a non-natural property to be one which is nondescriptive (in a sense not further specified), and he offers what he calls a "good" argument to show that goodness is non-natural in this sense. ${ }^{8}$ The argument, he says, contains two premises; actually, as I understand it, it contains several more, and runs as follows. (1) There are many different natural intrinsic properties which are ought-implying. ${ }^{9}(2)$ No natural intrinsic property (except possibly a disjunction of them all) is both entailed by all of these properties and ought-implying. (3) Goodness is not identical with each of these different natural intrinsic properties. (4) It is entailed by each of them. (5) It is not identical with a disjunction of them all. (6) It is ought-implying. (7) Therefore, goodness is not identical with any natural intrinsic property. Moore says that this argument is perfectly conclusive if (1) and (2) are true. This is obviously a slip on his part. It is conclusive only if premises (3) to (6) are also true. But of these premises only (3) is unquestionable. Premise (4) would be denied by those who regard goodness as not being intrinsic in Moore's sense, (5) involves the assumption that "good" in the sense of "intrinsically good" is not an ambiguous term, and (6) was once denied by Prichard and Carritt. However, there may still be good reasons for supposing these additional premises to be true, and I do not wish to question them. Nor am I concerned here to deny (1). What I wish to contend is that in asserting (2) Moore is so far from giving us a "good" argument as to be begging the question. To assert (2) one must 
know that goodness is not a natural intrinsic property which is both oughtimplying and entailed by all the natural properties referred to in ( 1 ).

To know this one must know: (a) that goodness is neither a natural property nor a disjunction of natural properties, (b) that it is not entailed by all the natural properties referred to in (1), or (c) that it is not oughtimplying.

Now (b) and (c) are ruled out by (4) and (6) respectively. Therefore, if one asserts (4) and (6), then before he can assert (2) he must know (a). Now (a) does not follow from (4) and (6) taken separately or together, for, as Moore admits, a natural intrinsic property may be resultant and ought-implying. Therefore, to know (a) one must know independently that goodness is not a natural intrinsic property. Hence, to assert (2) in conjunction with (4) and (6) is to assume that goodness is not a natural intrinsic property, and so to beg the question.

A. C. Ewing has also contended that goodness is non-natural (in Broad's sense apparently), ${ }^{10}$ but I have dealt with his arguments elsewhere. ${ }^{11}$ His main point is that the notion of goodness involves that of obligation and is therefore generically different from all natural notions. This, however, assumes that "good" is definable in terms of "ought" and that "ought" stands for a non-natural characteristic; his other arguments do not establish either of these assumptions, any more than they prove directly that goodness is non-natural. In fact, in order to make his point, Ewing appeals, not to any argument, but to inspection. "I see," he says, "that propositions about what is good in some senses of 'good' are propositions which cannot be analysed adequately in psychological terms." 12 This is as it should be, for inspection, if I am right in my estimate of his and other intuitionists' arguments, must in some sense be the ultimate court of appeal in this matter. Even so, his appeal to this tribunal is rather too facile, and others may well, on consulting it, receive a negative verdict, as I do (except in the case of moral value).

However, my concern here is with the arguments which are alleged to prove that goodness (intrinsic) is non-natural, and I believe I have shown them to be quite inconclusive or even question-begging. Hence, if careful inspection bears us out, we may still be naturalists about intrinsic value.13 Of course, these arguments cannot serve to establish the non-naturalness of moral value, rightness, or obligatoriness either, if I am right. This result is not entirely to my liking, as I am still inclined to be a non-naturalist about these. But, if one is to be a naturalist about intrinsic value, as I find myself being, one must answer said arguments, and, anyway, if they are in fact inconclusive or question-begging, nothing is to be gained by hiding this. As A. N. Prior has recently said, it is only confusing the issue for non-naturalists to go on misconceiving the grounds of their position. ${ }^{14}$ 


\title{
NOTES
}

II shall use "goodness" to mean "intrinsic goodness."

'See, e.g., P. A. Schilpp, ed., The Philosophy of G. E. Moore (Evanston, Ill.: Northwestern University Press, 1942), pp. 57-62, 581-92; W. D. Ross, The Right and the Good (Oxford: Clarendon Press, 1930), pp. 87, 114-22.

The Philosophy of G. E. Moore, pp. 62-65.

- This is not a tautology. A characteristic may be indefinable (and therefore indefinable in natural terms) and yet be natural, as yellow is according to Moore.

"M. E. Clarke, "Valuing and the Quality of Value," Journal of Philosophy, 35:10 (1938).

'See Moore, Philosophical Studies (London: Kegan Paul, 1922), pp. 253-75, and W. D. Ross, The Right and the Good.

${ }^{7} \mathrm{Cf}$. the example of yellow.

${ }^{8}$ The Philosophy of G. E. Moore, pp. 591-92, 605-6. He seems also to hold that goodness is intrinsic, resultant, and nonempirical, pp. 588, 592.

- For his definition of an ought-implying property, see pp. $603 \mathrm{ff}$.

${ }^{20}$ The Definition of Good (New York: MacMillan, 1947), chap. 2, especially pp. 74-75.

${ }^{11}$ Philosophical Review, 59:481-92 (1948).

${ }^{12}$ See pp. 43-44.

${ }^{23}$ It should be noted that many metaphysical idealists and theists are naturalists about intrinsic value in the sense of that term which is here in question.

${ }^{14}$ Logic and the Basis of Ethics (Oxford: Clarendon Press, 1949), p. vii.

\section{Mr. Edwards on "Ordinary Language and Absolute Certainty"}

\author{
by C. A. CAMPBELL
}

UNIVERSITY OF GLASGOW

I sHound like to be allowed to reply briefly to the criticism of myself which is the main burden of Paul Edwards' paper on "Ordinary Language and Absolute Certainty" in your January issue.

The particular argument he attacks is one which I used in the course of an attempt to refute Norman Malcolm's theory that the disagreement between the philosopher and the plain man about the "certainty" of some material object statements is merely a disagreement about the use of language. ${ }^{1}$ I sought to show, against Malcolm, that the ordinary usage of the phrase "known for certain" and the philosophical usage are in fact one and the same, namely, "known in a way which excludes all possibility of doubt"; and that the plain man's disagreement with the philosopher about 